\title{
Palliative sedation and oncological active treatment at the end of life; Is there any difference between the hospital and at home?
}

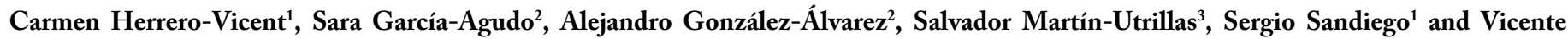 \\ Guillem-Porta ${ }^{1}$ \\ ${ }^{1}$ Department of Medical Oncology, Valencian Institute of Oncology, Valencia, Spain \\ ${ }^{2}$ Pharmacy Department, Obispo Polanco Hospital, Teruel, Spain \\ ${ }^{3}$ Palliative Care Unit, Valencian Institute of Oncology, Valencia, Spain
}

\begin{abstract}
Aim: The aim of this study is to analyze the use of palliative sedation and active oncological treatment at the end of life in terminal stage cancer in 2013 on the Medical Oncology and Palliative Home Care Integrated Service of the Valencian Institute of Oncology.

Method: Retrospective analysis of the palliative sedation until death registered on Medical Oncology ward from January to December 2013, and the recorded date of the last chemotherapy or anti-target treatment given. The data are analyzed using the SPSS version 20.0 statistic package.

Results: Total number of cases who received palliative sedation is 212 ; (71\%) 151 patients in the hospital and (29\%) 61 patients at home. The median age was 61 years (range 19-91 years old) with 32\% female and 68\% male. 39 patients (18\%) underwent treatment in the last 4 weeks of life and 17 patients (8\%) in their last 2 weeks of life. Of these 39 patients, $54 \%$ of them are older than 65 years and $30 \%$ older than 70 years.

Conclusions: The results in both groups (at home and in the hospital) were similar in sociodemographic and pathological patient profile and time from palliative sedation to death. The concept of aggressive chemotherapy or anti-target therapy in the group of patients analysed is similar to the literature review.
\end{abstract}

\section{Background}

The treatment of advanced stage cancer patients has seen extraordinary progress over the last years, and proof of this is the incorporation of new target-therapies [1]. Most of them can be administered orally, and it makes possible to give the drugs over longer period of time in order to prolong survival or/and control the symptoms. However, present clinical guidelines in Oncology (NCCN, NICE) recommended Palliative Care should be an integrated early part of continuing care for cancer patients $[2,3]$.

The patient requires a specific treatment for quality of life to be maintained in the final stage of life. This is the period of time when patients has an illness that is progressing and is going to be the cause of their death [4]. It is difficult to determine precisely when an advanced stage cancer patient is nearing the end of life. It is estimated that by the year 2020 there will be 15 million new cases of cancer and 10 million deaths [5].

Palliative sedation (PS) at the end of life is defined as monitored use of medications intended to induce a state of decreased or absent awareness (unconsciousness) in order to relieve the burden of otherwise intractable suffering in a manner that is ethically acceptable to the patient, family and health-care providers [6,7]. It has become an essential practice in palliative care, and it is often the key to solve critical situations in the management of symptoms at the end of life.

The clinical practice of PS, although not definitely standardized, might be different when it is carried out in the hospital or at home. When used at home, the absence of medical or nursing staff and the way of administration of drugs is often different. There is a large experience of PS at home in our country. Nevertheless, it is not easy to find in the literature comparative studies between PS at home and in the hospital.

Our hospital is a cancer center in Valencia, Spain, where diagnosis, treatment and research is conducted. As many other centers in Spain there exists a hospital-based home-care service. This kind of clinical support, known as "Hospitalización a domicilio", is a frequently offered to advanced cancer patients and their families, especially when home is chosen as the best place to die. As in many other countries, in Spain clinical practice guidelines $[8,9]$ are based in low evidence degrees. To determine the best clinical practice in our center, either for inpatients or at home, we designed a descriptive study to know the profile of the patient to whom PS was administered, the drugs used and the evolution to death.

Correspondence to: Carmen Herrero-Vicent, Department of Medical Oncology, Valencian Institute of Oncology, Valencia, Spain, Tel: 34 620519816; E-mail: carmendcn@gmail.com

Key words: palliative sedation, advanced cancer, hospital, palliative home care, aggressive treatment

Received: April 06, 2017; Accepted: May 04, 2017; Published: May 06, 2017 


\section{Aim}

To describe in this setting the profile of cancer patient receiving PS, drugs and doses used and the time from the PS to the end of life, and differences by location.

To describe between the last active oncological treatment and the date of PS and the differences by location

\section{Method}

\section{Design of the study: Observational, retrospective study}

Study population: Patients who died during admission in Medical Oncology Department admitted in conventional hospitalisation or by the Home Care Unit in the Valencian Institute of Oncology.

Inclusion criteria: Patients who received palliative sedation at the end of life from January to December 2013.

Sources of data: The clinical reports of all the patients who died in 2013 either in our hospital or in our hospital-based home-care service were reviewed. Those who died in the intensive care unit were excluded. We included reports from patient who had received PS previous to death.

Variables: Out of clinical reports, we collected data about the patient (age, gender), the clinical situation (primary tumor, refractory symptom), the drugs used (doses of induction and maintenance, way of administration), and the time from PS to death. In addition, we wanted to know the time from administration of the last antitumor treatment (including chemotherapy, radiotherapy, hormone therapy and others) to PS decision. Due to the concept of "aggressive" oncological active treatment of cancer is defined by the proportion of patients that have chemotherapy during the 14 days prior their death.

Statistical analysis: Data were analyzed using SPSS Version 20.0. The influence of age, gender, primary tumor, refractory symptom, drugs used way of administration, and the place where the patient dies were determined using chi-square test. A $\mathrm{P}$ value of $<0-05$ denoted statistical significance.

\section{Results}

We identified 343 patients who died in our center with advanced cancer in the study period. Of all them, 212 of them received PS, 151 patients $(71 \%)$ in the hospital and 61 patients $(29 \%)$ at home. The number of sedations is reflected in Table 1 .

The median age was 61 years (range 19-91 years old) with $32 \%$ female and $68 \%$ male. There were no differences between patients treated at home and at hospital: Median age at home was 70 years and at hospital 63 years $(\mathrm{p}=0.38)$. Age compared between home and Hospital is reflected in Table 2 and Figure 1.

There was a balance of general condition between patients who received PS at hospital and at home: $58 \%$ of patients who received PS at hospital presented a Karnofsky Performance State score $<50$ meanwhile $54 \%$ of patients who received PS at home $(\mathrm{p}=0.15)$.

Table 1. Number of patients and percentages of palliative sedation (PS) and deaths.

\begin{tabular}{|l|c|c|c|}
\hline & $\mathbf{N}^{\mathbf{0}}$ PS & $\mathbf{N}^{\mathbf{0}}$ Death & $\mathbf{\%}$ \\
\hline Total Hospital & - & 387 & - \\
\hline Hospital+Home & 212 & 343 & $61.18 \%$ \\
\hline Hospital & 151 & 253 & $59.68 \%$ \\
\hline At Home & 61 & 90 & $67.77 \%$ \\
\hline
\end{tabular}

Table 2. Patient's median age and comparison between hospital and home.

\begin{tabular}{|l|c|c|c|}
\hline & N & Median & DS \\
\hline Total & 212 & 65.08 & 11.521 \\
\hline Home & 61 & 70.02 & 10.990 \\
\hline Hospital & 151 & 63.09 & 11.159 \\
\hline $\mathrm{p}=0.385$ & & & \\
\hline
\end{tabular}

The most common primary tumours were gastrointestinal (41 patients, 19.3\%), breast (39 patients, 18.4\%), genitourinary (32 patients, 15.1\%), lung (32 patients, 15.1\%), melanoma (19 patients, $9 \%)$, gynaecologic (19 patients, $9 \%$ ), sarcoma (12 patients, 5.7\%), head and neck (12 patients, 5.7\%), brain ( 3 patients, $1.4 \%$ ), and lymphoma (3 patients, 1.4\%). All of them at stage IV. There were no differences between primary tumours at home and at hospital.

Common refractory symptoms were: delirium (37\%); dyspnoea (33\%) and pain (29\%). There were no differences between two goups: At home patients presented delirium (36.8\%); dyspnoea $(28.8 \%)$; pain $(33 \%)$ and haemorrhage (1.4\%). At hospital patients presented delirium (35.8\%); dyspnoea (28.2\%); pain (38.4\%) and haemorrhage $(0.7 \%) \mathrm{p}=0.85$. Primary tumor \& refractory symptom compared is reflected in Figures 2 and 3.

The drug used was Midazolam in 190 patients (90\%). The route of administration was intravenous in 148 patients (70\%) and subcutaneous in 64 patients (30\%). Between two groups: all patients at hospital used intravenous administration meanwhile at home $86 \%$ used subcutaneous administration $(\mathrm{p}=0.01) .53 \%$ of patients required more than $45 \mathrm{mg}$ / day. Between two groups: $51 \%$ patients at hospital and at home $64 \%$ used used more than $45 \mathrm{mg} /$ day of Midazolam ( $\mathrm{p}=0.25)$. Way, drug, initial dose, maximum dose and other drugs: Table 2 (and compared) (Figures 4-6).

$80 \%$ of the patients died within 48 hours after starting the PS. At home $34 \%$ of patients died in less than 24 hours and $43 \%$ from $24-48$ hours after starting PS. Meanwhile at hospital $38 \%$ in less than 24 hours and $44 \%$ from $24-48$ hours $(\mathrm{p}=0.55$ ). The length of time between the last active oncological treatment and the date of death was 21 days (23 days in the hospital and 20 days at home) (Figure 7). Time to death and time from last treatment to death: Table 3 (and compared) (Figure 8).

Of 212 patients cases included in the study, 39 patients (18\%) underwent treatment in the last 4 weeks of life and 17 patients (8\%) in their last 2 weeks of life.

Of these 39 patients who received active treatment in last 4 weeks, $54 \%$ of them were older than 65 years and $30 \%$ older than 70 years. In addition, there are 3 episodes of toxic death recorded.

\section{Conclusions and discussion}

In the time period analysed there were 343 deaths in the Valencian Institute of Oncology. The incidence of PS for patients with refractory symptoms in the group under study is $212(61 \%)$. In the literature the figure ranges from 16-52\% [10]. Moreover, 151 patients (71\%) received PS in the hospital and 61 patients (29\%) at home. This fact leads us to reflect upon two things: Our hospital is a monographic cancer center and the patient or their family members prefer the death occur in a hospital.

Median age in or study population was 61 years old. By the year 2020 there will be a total of 242000 new cases of cancer, with $38.6 \%$ affecting people under 65 years old [11]. This fact reflects that over the 


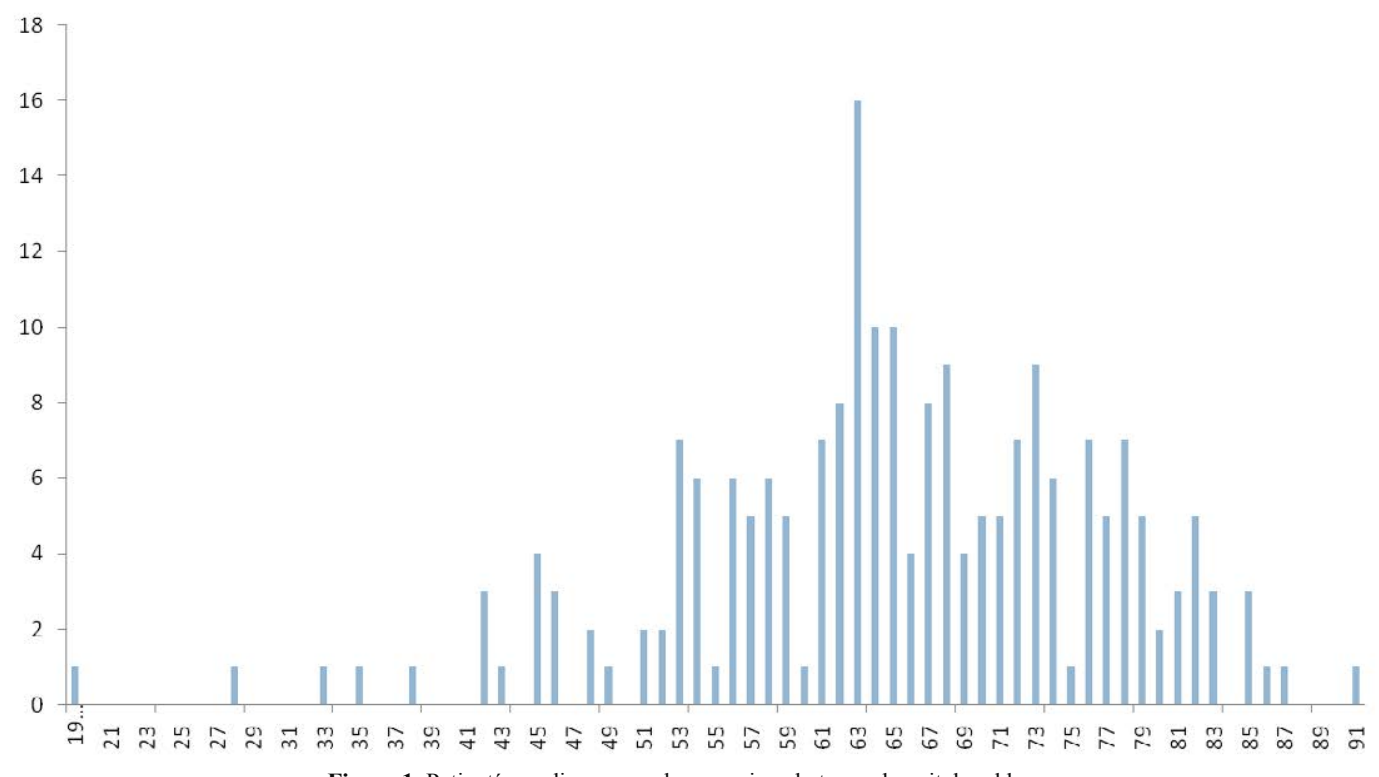

Figure 1. Patient's median age and comparison between hospital and home.

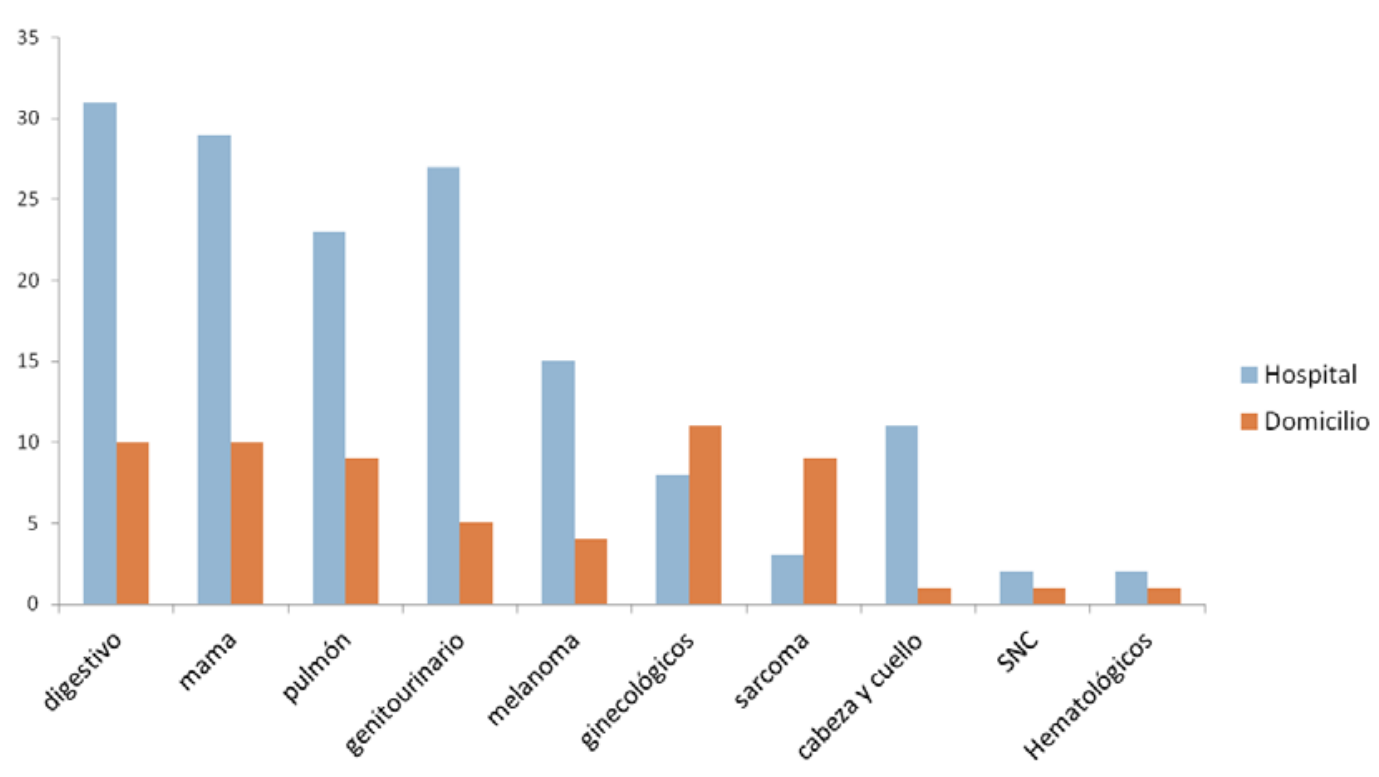

Figure 2. Primary site cancer.
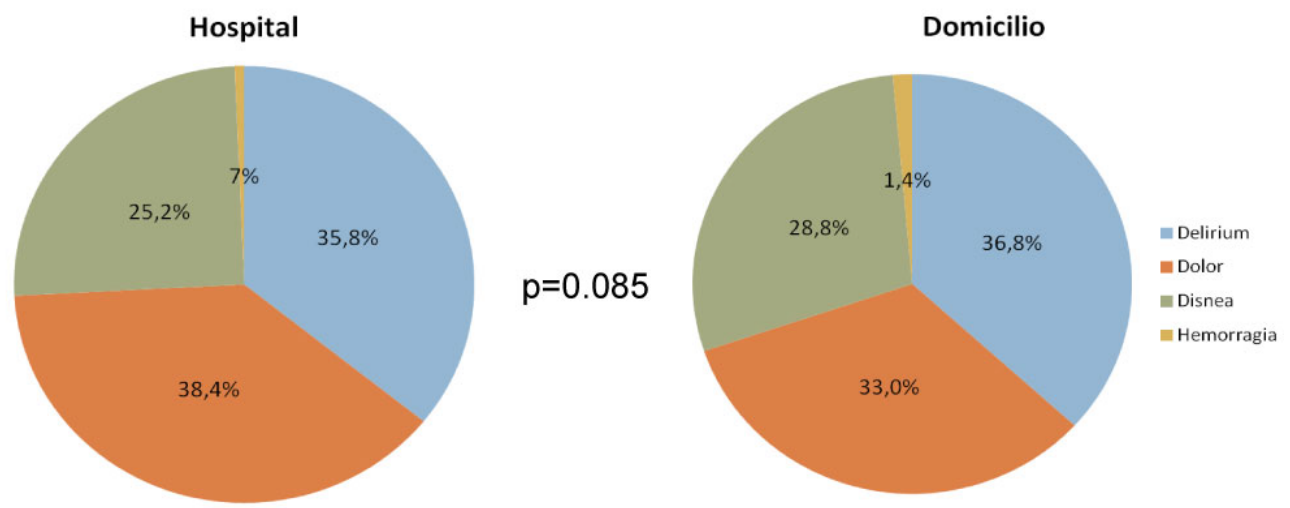

Figure 3. Refractory symptoms and comparison between hospital and home. 


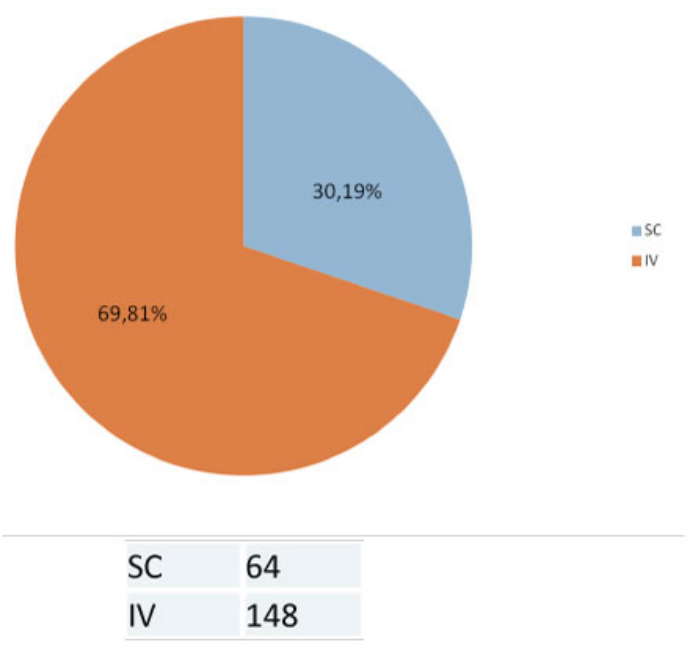

Figures 4. Way, drug, maximum dose of Midazolam compared.

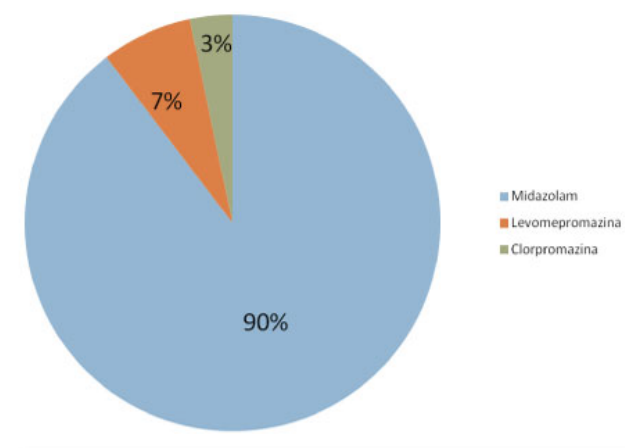

$\begin{array}{ll}\text { Midazolam } & 190 \\ \text { Levomepromazine } & 15 \\ \text { Clorpromazine } & 7\end{array}$

Figures 5. Way, drug, maximum dose of Midazolam compared. last 10 years cancer suffering have become younger [12].

The most frequent categories of refractory symptoms are: delirium, dyspnoea, pain, psychosocial suffering and existential stress $[13,14]$. Survival time once the patient received PS, $80 \%$ was less than 48 hours.

Statistically significant differences found between hospitals and home in the administration route and doses can be explained by different clinical management of the patient and the procedures used. However, the results in both groups were similar in sociodemographic and pathological patient profile and time from sedation to death. This is the first comparative study carried out in our region.

On the other hand, at present there is no clearly drawn line between palliative treatment in order to control symptoms and oncological active treatment like chemotherapy, new targets, radiotherapy. The toxicity generated by an oncological active treatment can lead to a patient preferring not or have it or, it is started, then refusing to continue with it [15]. The concept of "aggressive" oncological active treatment of cancer is defined by the proportion of patients that have chemotherapy during the 14 days prior their death, the average number of dose of chemotherapy and the date of death, the number of regimens and cycles received, the average length of time of chemotherapy, the number of visits to Emergencies in the last month of life and admissions into the Intensive Care Unit in the last month [16,17].

In our study 39 patients (18\%) underwent oncological active treatment (chemotherapy, anti-target treatment) in the last 4 weeks of life and 17 patients (8\%) in their last 2 weeks of life. Our results meet the criteria for aggressive cancer treatment in that clinical scenario. Despite this, the incidence of toxic death is only 3 cases.

In 2004, Young How and collaborators studied how often chemotherapy was given in 17 hospitals in Korea to oncologic patients in the final stage of life; $30 \%$ in the last month of life [18]. Meanwhile, in a study carried out among American Medicare beneficiaries, chemotherapy was administered to $9 \%$ in the last month [19]. Another study that analysed the length of time between the last chemotherapy administered and the death in 255 cases, $12.5 \%$ of them received

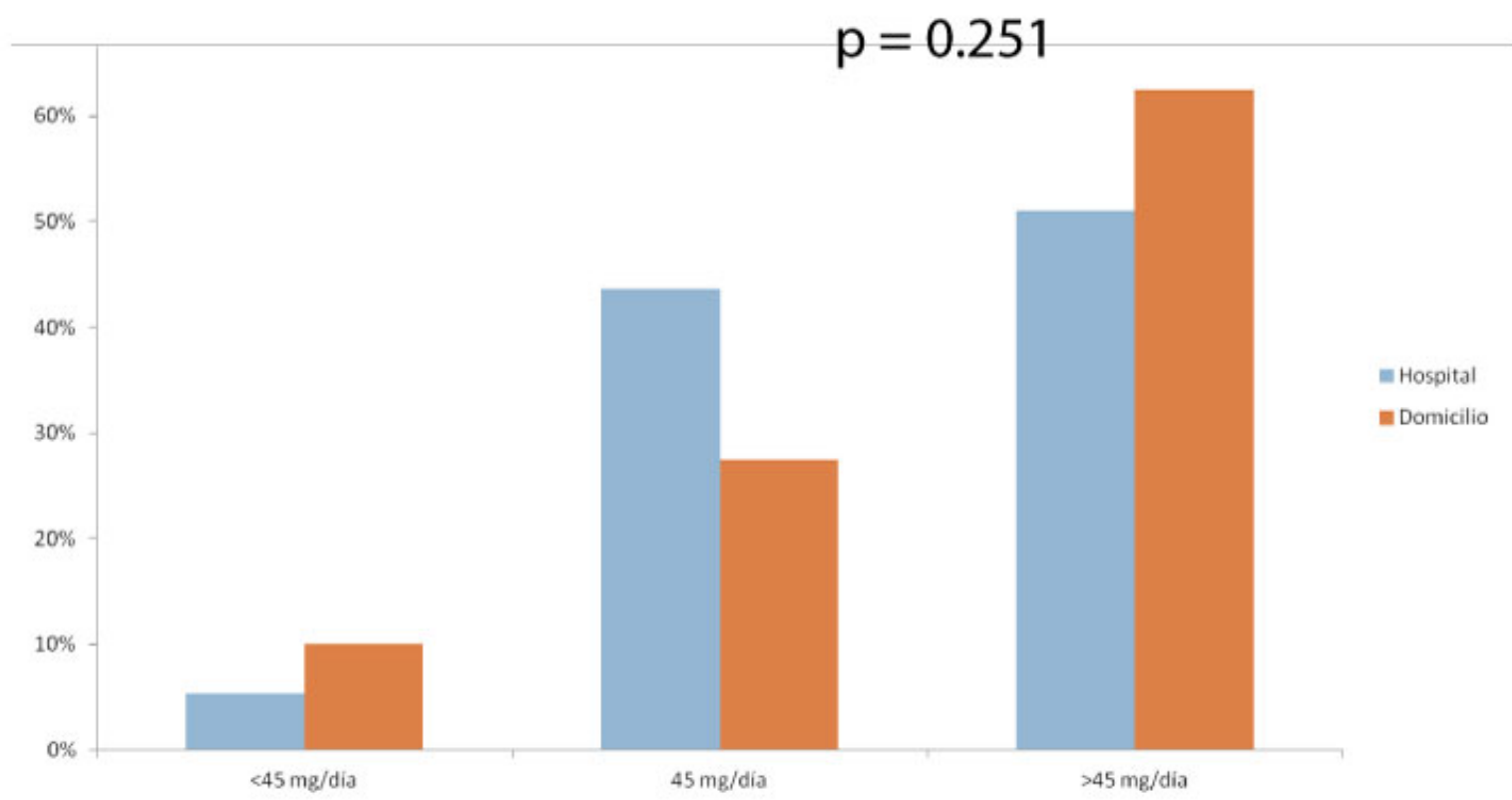

Figures 6. Way, drug, maximum dose of Midazolam compared. 
Table 3. Time from last treatment to death.

\begin{tabular}{|l|l|c|c|c|}
\hline \multicolumn{2}{|c|}{} & N & Mean & Deviation \\
\hline $\begin{array}{l}\text { Last Treatment } \\
\text { (days) }\end{array}$ & Hospital & 151 & 23.15 & 14.333 \\
\cline { 2 - 5 } & Home & 61 & 20.49 & 10.807 \\
\hline
\end{tabular}

chemotherapy in the last 30 days [20].

In the Marqués de Valdecilla Hospital in Santander (Spain) the chemotherapy at the end of life and the percentage of patients who received Palliative Home Care integrated service have been studied.
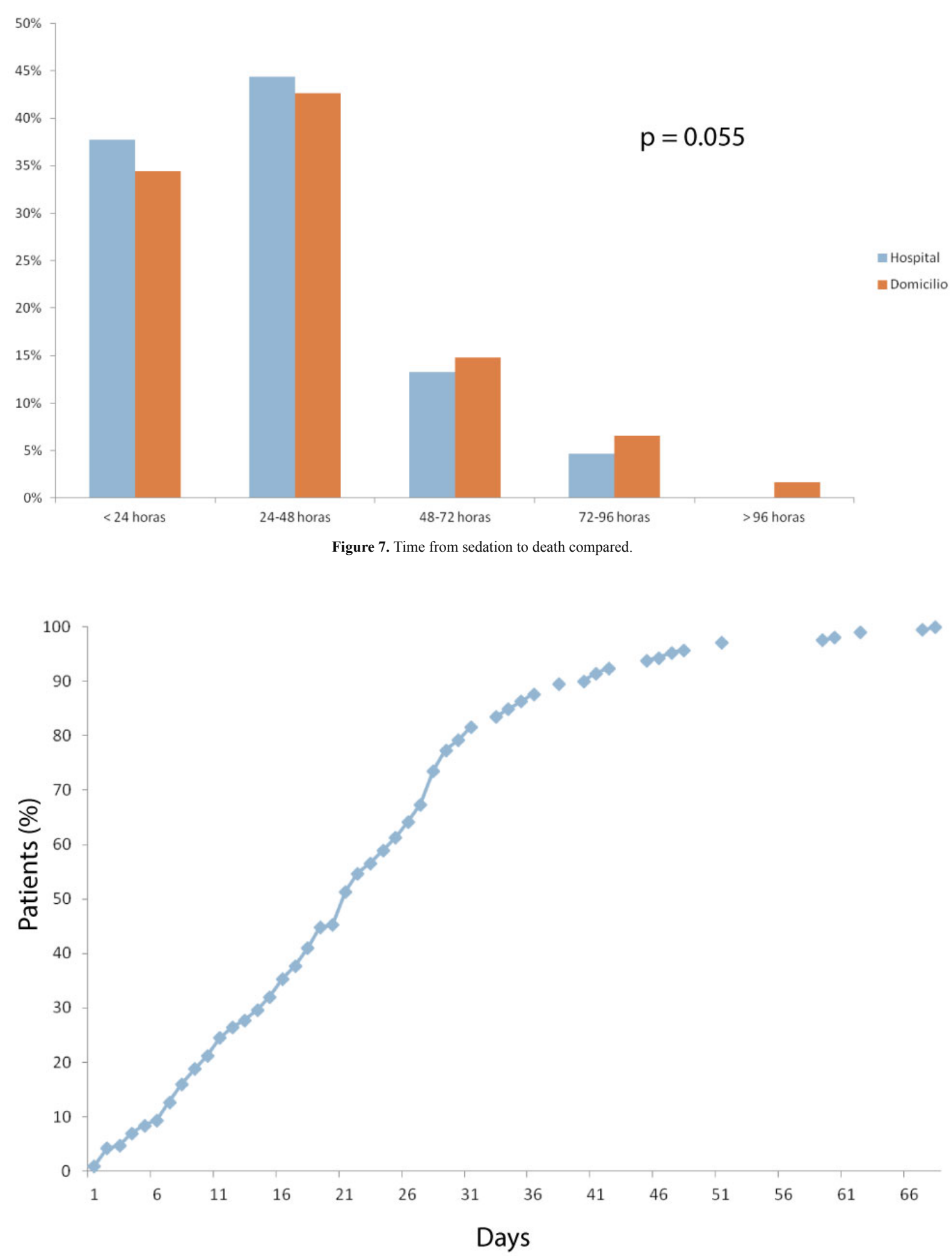

Figure 8. Time from last treatment to death. 
Between 2009 and 2010, 302 patients were recorded and 55.6\% received chemotherapy at the last month, and $33.8 \%$ in the last two weeks [21].

To sum up, the results in both groups (at home and in the hospital) were similar in sociodemographic and pathological patient profile and time from palliative sedation to death. The concept of aggressive chemotherapy or anti-target therapy in the group of patients analysed is similar to the literature review. The limitation of this study results from the fact that it is not possible to draw generalizable conclusions because it is a descriptive study. However, lay the foundations upon which further research can be carried out.

\section{References}

1. Sanz Ortiz J (2003) Nuevas dianas moleculares en la terapia del cáncer Tienen función paliativa? Med Pal 10(4): 220-225.

2. Malin JL (2004) Bridging the divide: integrating cancer-directed therapy and palliative care. J Clin Oncol 22: 3438-3440. [Crossref]

3. National Consensus Project for Quality Palliative Care (2004) Clinical Practice Guidelines for quality palliative care. http://www.nationalconsensusproject.org

4. Lorenz KA, Lynn J, Dy SM, Shugarman LR, Wilkinson A, et al. (2008) Evidence for improving palliative care at the end of life: a systematic review. Ann Intern Med 148 : 147-159. [Crossref]

5. Ferlay J, Bray F, Pisani P, Parkin DM (2001) GLOBOCAN 20.00: cancer incidence, mortality and prevalence word wide. Version 1.0. IARC CancerBase N. 5.Lyon IARC Press.

6. Cherny NI, Radbruch L, Board of the European Association for Palliative Care (2009) European Association for Palliative Care (EAPC) recommended framework for the use of sedation in palliative care. Palliat Med 23: 581-593. [Crossref]

7. Porta Sales J, Ylla-Catalá Boré, Estibalez Gil I, Griman Malet A, Lafuerza Torres M, et al. (1994) Estudio multicéntrico catalana-balear sobre la sedación Terminal en Cuidados Paliativos. Med Pal 6(4): 153-158.

8. Paliativos GdTdlGdPCsC (2008) Guía de Práctica Clínica sobre Cuidados Paliativos Vitoria-Gasteiz: Servicio Central de Publicaciones del Gobierno Vasco.
9. Organización Médica Colegial (2011) Sociedad Española de Cuidados Paliativos. Guía de Sedación Paliativa. Madrid.

10. Cherny NI, Portenoy RK (1994) Sedation in the management of refractory symptoms: guidelines for evaluation and treatment. J Palliat Care 10: 31-38. [Crossref]

11. GLOBOCAN (2008) http://globocan.iarc.fr/factsheets/cancers/all.asp

12. Raby B, Pater J, Mackillop WJ (1995) Does knowledge guide practice? Another look at the management of non-small-cell lung cancer. J Clin Oncol 13: 1904-1911. [Crossref]

13. Porta-Sales J, Núñez Olarte JM, Altisent Trota R, Bisbert Aguilar A, Loncan Vidal P, et al. (2002) Aspectos éticos de la sedación en cuidados paliativos. Med Pal 9(1): 41-46.

14. Doyle D (1992) Have we looked beyond the physical and psychosocial? J Pain Symptom Manage 7: 302-311. [Crossref]

15. Silvestri G, Pritchard R, Welch HG (1998) Preferences for chemotherapy in patients with non-small cell lung cancer: descriptive study based scripted interviews. BMJ 317 : 771-775

16. Keam B, Oh DY, Lee SH, Kim DW, Kim MR, et al. (2008) Aggressiveness of cancercare near the end-of-life in Korea. Jpn J Clin Oncol 38: 381-386. [Crossref]

17. Earle CC, Landrum MB, Souza JM, Neville BA, Weeks JC, et al. (2008) Aggressiveness of cancer care near the end of life: is it a quality-of-care issue? J Clin Oncol 26: 38603866. [Crossref]

18. Yun YH, Miyoung K, Sang Min P, Samyong K, Jong Soo C, et al. (2007) Chemotherapy use and associated factors among cancer patients near the end of life. Oncology 72: $164-171$

19. Emanuel EJ, Young-Xu Y, Levinsky NG, Gazelle G, Saynina O, et al. (2003) Chemotherapy use among Medicare beneficiaries at the end of life. Ann Intern Med 138: 639-643. [Crossref]

20. Hashimoto K, Yonemori K, Katsumata N, Hotchi M, Kouno T, et al. (2009) Factors that affect the duration of the interval between the completion of palliative chemotherapy and death. Oncologist 14: 752-759.

21. Sanz Ortiz J (2012) Chemotherapy at the end of life: up until when? Clin Trans Oncol 14: 667-674. [Crossref]

Copyright: (C2017 Herrero-Vicent C. This is an open-access article distributed under the terms of the Creative Commons Attribution License, which permits unrestricted use, distribution, and reproduction in any medium, provided the original author and source are credited. 